\title{
Aspirin Dose and Treatment Outcomes in Kawasaki Disease: A Historical Control Study in Japan
}

\author{
Yu Ito ${ }^{1}$, Takuya Matsui ${ }^{2}$, Kota Abe ${ }^{1}$, Takafumi Honda ${ }^{2}$, Kumi Yasukawa ${ }^{2}$, \\ Jun-ichi Takanashi ${ }^{1}$ and Hiromichi Hamada ${ }^{1 *}$ \\ ${ }^{1}$ Department of Pediatrics, Tokyo Women's Medical University Yachiyo Medical Center, Chiba, Japan, ${ }^{2}$ Department of \\ Pediatric Intensive Care, Tokyo Women's Medical University Yachiyo Medical Center, Chiba, Japan
}

\section{OPEN ACCESS}

Edited by:

Mamoru Ayusawa,

Nihon University Itabashi

Hospital, Japan

Reviewed by:

Michael Portman

University of Washington,

United States

Kentaro Ueno,

Kagoshima University Hospital, Japan

Kazuyuki lkeda,

Kyoto Prefectural University, Japan

*Correspondence:

Hiromichi Hamada

hiromichi.hamada@gmail.com

Specialty section:

This article was submitted to

Pediatric Cardiology,

a section of the journal

Frontiers in Pediatrics

Received: 28 January 2020

Accepted: 22 April 2020

Published: 14 May 2020

Citation:

Ito Y, Matsui T, Abe K, Honda T,

Yasukawa K, Takanashi Jl and Hamada H (2020) Aspirin Dose and

Treatment Outcomes in Kawasaki Disease: A Historical Control Study in Japan. Front. Pediatr. 8:249.

doi: 10.3389/fped.2020.00249
Aspirin has been used as a concomitant drug in the treatment of Kawasaki disease (KD). In recent years, there has been discussion concerning whether high-dose aspirin is appropriate for treatment in the acute phase of $\mathrm{KD}$. We retrospectively investigated the incidence of coronary artery abnormalities (CAAs) and the antipyretic effect of 30 to $50 \mathrm{mg} / \mathrm{kg} /$ day aspirin, the minimum and the maximum approved doses in Japan. This was a single-center, non-randomized, retrospective, historical cohort study. Patients were routinely treated with 50 mg/kg/day aspirin (50-mg Group) between 2007 and April 2014, and with 30 mg/kg/day aspirin (30-mg Group) between May 2014 and 2016. All patients were given initial and, if necessary, subsequent intravenous immunoglobulin (IVIG) $2.0 \mathrm{~g} / \mathrm{kg}$. The primary endpoint was incidence of CAAs defined as a CA diameter with a $Z$ score $\geq 2.5$ at treatment week 4 . The secondary endpoint was incidence of further treatment. Incidences were compared using inverse probability weighting analysis adjusting for age, sex, and risk scores. In 587 patients, there was no significant difference in incidence of CAAs (odds ratio in 30-mg Group 0.769, 95\% confidence interval (Cl): $0.537-1.101, p=0.151$ ). Risk of further treatment after the first IVIG in the 30-mg Group was significantly higher than that in the 50-mg Group (odds ratio 1.379, 95\% Cl: $1.051-1.811, p=0.021$ ). Although this study has some limitations, the findings suggest that aspirin $50 \mathrm{mg} / \mathrm{kg} /$ day may have no significant effect on improving incidence of CAAs compared with $30 \mathrm{mg} / \mathrm{kg} /$ day but may have a lower rate of further treatment.

Keywords: aspirin, treatment, coronary artery, Kawasaki disease (KD), immunoglobulin

\section{INTRODUCTION}

Kawasaki disease (KD), which is an acute vasculitis in young children and causes coronary artery abnormalities (CAAs) such as coronary artery aneurysm and dilation, is the leading cause of acquired heart disease in children in developed countries $(1,2)$. In the five decades since the initial recognition of $\mathrm{KD}$, the standard treatment is a combination of intravenous immunoglobulin (IVIG) and acetylsalicylic acid (ASA) (3). High-dose ( $80-100 \mathrm{mg} / \mathrm{kg})$ and medium-dose (30-50 $\mathrm{mg} / \mathrm{kg}$ ) ASA have been recommended as standard treatment during the acute febrile phase by the American Heart Association (AHA) and Japanese Society of Pediatric Cardiology and Cardiac Surgery (JSPCCS) $(4,5)$. 
ASA was first confirmed to be effective for $\mathrm{KD}$ in the latter half of the 1970s in Japan. That prospective study compared ASA, flurbiprofen, and prednisolone plus dipyridamole (6). At 1 month after onset, ASA could not prevent the incidence of CAAs, but at 1 year after onset, only $1 \%$ of ASA-treated patients had CAAs. These results were far better compared with $12 \%$ in the flurbiprofen-treated group and $9 \%$ in the prednisolone plus dipyridamole-treated group, indicating the superiority of ASA (4). Mortality dropped from 1.7 to $0.2-0.3 \%$ after the ASA treatment was adopted (7). A US study prior to the spread of immunoglobulin therapy has also shown that ASA suppresses the development of CAAs (8).

In the 1990s, IVIG became the mainstay of treatment, and when the development of CAAs was the final prognosis, the impact of ASA became less pronounced $(9,10)$. In recent years, some retrospective studies have raised the question of whether high-dose and medium-dose ASA would be appropriate for KD treatment in terms of risk-benefit (11-14). Starting treatment with high or medium doses of ASA ( $\geq 30 \mathrm{mg} / \mathrm{kg}$ /day) was found not to prevent CAAs (11-14).

In Japan, the Pharmaceuticals and Medical Devices Agency has approved ASA 30-50 mg/kg/day for KD. However, no studies have investigated ASA dose and outcomes in KD within the recent IVIG era in Japan. For 11 years now we have treated KD patients with a unified treatment protocol of IVIG and ASA as first-line therapy. Between January 2007 and April 2014, patients received $50 \mathrm{mg} / \mathrm{kg} /$ day ASA. After May 2014, patients were given $30 \mathrm{mg} / \mathrm{kg} /$ day ASA. In this study, we retrospectively investigated differences in the incidence of CAAs as well as the antipyretic effect between historical control $50 \mathrm{mg} / \mathrm{kg} /$ day and $30 \mathrm{mg} / \mathrm{kg} /$ day ASA at a single center in Japan.

\section{METHODS}

This single-center, non-randomized, retrospective, historical cohort study had a target population that comprised 587 children between 0 and 12 years of age diagnosed with complete or incomplete KD between 2007 and 2016 at Tokyo Women's Medical University Yachiyo Medical Center, Chiba, Japan. Between January 2007 and April 2014, patients received 50 $\mathrm{mg} / \mathrm{kg} /$ day ASA. Between May 2014 and September 2016, patients were given $30 \mathrm{mg} / \mathrm{kg} /$ day ASA.

Inclusion criteria were children with a diagnosis of $\mathrm{KD}$ who were treated with IVIG and ASA. Given that the diagnosis of KD cannot be confirmed definitively, patients were eligible if the clinical suspicion of KD was such that treatment with IVIG was deemed clinically indicated.

Exclusion criteria were as follows: patients for whom a final diagnosis of $\mathrm{KD}$ was clearly ruled out; patients who had preexisting CAAs before treatment diagnosed at bedside according to the Japanese Ministry of Health, Labour and Welfare criteria (15), which are based on absolute values $(\geq 3 \mathrm{~mm}$ in children $<5$ years old, $\geq 4 \mathrm{~mm}$ in children $\geq 5$ years old); patients who had received any treatment for $\mathrm{KD}$ at other medical hospital before arriving at our institution; patients who were enrolled in a clinical study and had received cyclosporine with IVIG plus aspirin as first-line therapy (16).

Research Ethics Board approval was granted at Tokyo Women's Medical University (number 3636-R2). Only anonymous retrospective data were obtained for this study, and the requirement for patient consent was waived by the Research Ethics Board.

Patients received initial IVIG $2.0 \mathrm{~g} / \mathrm{kg}$ for $24 \mathrm{~h}$ and ASA. An additional dose of IVIG $2.0 \mathrm{~g} / \mathrm{kg}$ was administered to patients who were non-responders, defined as body temperature $\geq 37.5^{\circ} \mathrm{C}$ at $48 \mathrm{~h}$ after initiation of primary therapy, and those who had $\mathrm{KD}$ relapse, defined as a return of fever $\left(\geq 37.5^{\circ} \mathrm{C}\right)$ without another likely source after $\mathrm{a} \geq 48$-h afebrile period from the initiation of primary therapy. Patients whose body temperature did not drop to below $37.5^{\circ} \mathrm{C}$ at $24 \mathrm{~h}$ after the initiation of the second dose of IVIG received cyclosporine or/and a third dose of IVIG as third-line therapy.

Between January 2007 and April 2014, patients received 50 $\mathrm{mg} / \mathrm{kg} /$ day ASA (ASA 50-mg Group). Between May 2014 and September 2016, patients were given $30 \mathrm{mg} / \mathrm{kg} /$ day ASA (ASA 30 $\mathrm{mg}$ Group). At $48 \mathrm{~h}$ after defervescence, aspirin dose was reduced to $5 \mathrm{mg} / \mathrm{kg} /$ day in all patients. Low-dose ASA was continued for 4 to 6 weeks.

The primary endpoint was the incidence of CAAs at treatment week 4. CAAs were diagnosed according to $\mathrm{Z}$ scores in Japanese children-echocardiographic measurements of the internal diameter normalized by body surface area-of coronary artery dimensions for the following three segments: proximal right coronary artery, left main coronary artery, and proximal left anterior descending artery (17). The maximum $\mathrm{Z}$ score was defined by the largest $\mathrm{Z}$ score in the three segments. CAAs were defined as present when the maximum $Z$ score was $\geq 2.5$, according to 2017 AHA guidelines. The value of the $Z$ score was retrospectively calculated using absolute diameters $(\mathrm{mm})$ in the echo reports at 1 month after onset.

The secondary endpoint was the incidence of second- and third-line therapy in the two treatment groups.

Adverse events were extracted from elevated liver enzymes, anemia, and bleeding. The incidences of elevated liver enzymes in ASA 50-mg Group and ASA 30-mg Group were compared. Elevated liver enzymes was defined as aspartate aminotransferase $>50 \mathrm{U} / \mathrm{L}$ and alanine aminotransferase $>50 \mathrm{U} / \mathrm{L}$ in the convalescent phase of KD. Differences in hemoglobin levels before and after the first IVIG dose were compared between the two groups. The incidence of severe bleeding or digestive symptoms suggesting gastritis or gastric ulcer was also compared between the two groups.

\section{Statistical Analysis}

We used a non-inferiority design to assess whether the risk ratio of CAAs between treatment groups would remain within the $95 \%$ confidence interval (CI) of a predefined clinically acceptable margin. In primary endpoint and secondary endpoint, data were adjusted by inverse probability weighting method for age, sex, and risk scores, and logistic regression was performed. A regression coefficient test was performed using the Wald test, and a $p<0.05$ was considered significant. 
TABLE 1 | Patient characteristics.

\begin{tabular}{|c|c|c|c|}
\hline Characteristic & $\begin{array}{c}\text { ASA 50-mg } \\
\text { Group } n=414\end{array}$ & $\begin{array}{c}\text { ASA 30-mg } \\
\text { Group } n=173\end{array}$ & $p$-value \\
\hline Age, years & $2.6(1.9)$ & $2.7(2.1)$ & $0.628^{\star a}$ \\
\hline Age $<1$ year at diagnosis, $\%$ & $22.2 \%$ & $24.2 \%$ & $0.680^{* b}$ \\
\hline Male sex, \% & $57.6 \%$ & $54.0 \%$ & $0.376^{\star b}$ \\
\hline Risk score (Kobayashi) & $3.5(2.3)$ & $3.6(2.6)$ & $0.837^{\star a}$ \\
\hline $\begin{array}{l}\text { Day of illness at first IVIG } \\
\text { treatment, days }\end{array}$ & $5.2(1.6)$ & $5.1(1.3)$ & $0.339^{\star a}$ \\
\hline Hemoglobin, g/dL & $11.3(1.2)$ & $11.6(1.0)$ & $0.830^{\star a}$ \\
\hline $\begin{array}{l}\text { White blood cell count, } \\
\times 10^{3} / \mu \mathrm{L}\end{array}$ & $13.9(4.4)$ & $13.9(4.6)$ & $0.851^{* a}$ \\
\hline $\begin{array}{l}\text { Neutrophils } \geq 80 \% \text { at } \\
\text { diagnosis }\end{array}$ & $23.7 \%$ & $23.7 \%$ & $0.423^{\star c}$ \\
\hline Platelet count, $\times 104 / \mu \mathrm{L}$ & $33.2(10.2)$ & $32.1(9.3)$ & $0.053^{\star c}$ \\
\hline C-reactive protein, $\mathrm{mg} / \mathrm{dL}$ & $7.5(4.6)$ & $8.3(4.7)$ & $0.373^{\star c}$ \\
\hline Albumin, g/dL & $3.9(0.3)$ & $3.9(0.4)$ & $0.842^{* c}$ \\
\hline $\mathrm{Na}, \mathrm{mEq} / \mathrm{L}$ & $134(2.6)$ & $134(2.9)$ & $0.410^{\star c}$ \\
\hline $\begin{array}{l}\text { Aspartate aminotransferase, } \\
\mathrm{U} / \mathrm{L}\end{array}$ & $104(215)$ & $121(240)$ & $0.183^{\star c}$ \\
\hline
\end{tabular}

Data are shown as the mean $(S D)$ or percentage.

*a Welch's t-test.

*bearson's $\chi^{2}$ test.

${ }^{\star c}$ t-test, two-sided.

Items under patient characteristics were assessed using Welch's $t$-test, Pearson's $\chi^{2}$ test, or a two-sided $t$-test. The incidence of adverse events was assessed using Fisher's exact test. Two-tailed $P<0.05$ was considered statistically significant.

\section{RESULTS}

A total of 655 patients were identified and screened for eligibility. Of them, 68 were excluded for the following reasons: 8 patients had CAAs before treatment; 39 patients had received any treatment for $\mathrm{KD}$ at other hospitals before referral to our institution; and 21 patients were enrolled in a clinical study and received cyclosporine with IVIG plus ASA as first-line therapy. The 587 remaining patients were included in the final analysis. Among them, 414 patients were routinely prescribed $50 \mathrm{mg} / \mathrm{kg} /$ day ASA between January 2007 and April 2014 (ASA 50-mg Group). The remaining 173 patients were routinely prescribed $30 \mathrm{mg} / \mathrm{kg} /$ day ASA between May 2014 and September 2016 (ASA 30-mg Group).

(Table 1) presents the characteristics of the study population. Both groups were similar in age, sex, risk scores (Kobayashi score for predicting resistance to IVIG) (18), number of days of fever before the first IVIG dose, C-reactive protein before treatment, and hemoglobin levels.

Our primary outcome, the presence of CAAs, was observed in 70 patients $(12 \%)$ in total. Of these, number of patients with small CAAs ( $\mathrm{z}$ score $\geq 2.5$ but $<5$ ), medium-sized CAAs, and large-sized CAAs in each treatment group are shown in (Table 2A). (Table 2B) presents the proportion of patients with CAAs according to treatment groups as well as the unadjusted and adjusted risk ratios. The incidence of CAAs was not significantly different between the ASA 50-mg Group and the ASA 30-mg Group.

For the secondary endpoint, requiring further treatment after the first IVIG dose was observed in 143 patients (24\%) in total. The risk was significantly higher in the ASA 30-mg Group than in the ASA 50-mg Group (Tables 3A,B).

For safety outcomes, the incidences of elevated liver enzymes at convalescent phase were similar between the two groups (Table 4A). There was no significant difference between the two groups in the reduction of hemoglobin before and after the first IVIG (Table 4B). No severe hemorrhagic complications nor digestive symptoms were observed in either group.

\section{DISCUSSION}

The results of our study suggest that using $30 \mathrm{mg} / \mathrm{kg} /$ day ASA, which is the lower limit of the approved dose for acute KD in Japan, is not inferior to $50 \mathrm{mg} / \mathrm{kg} /$ day ASA, which is the upper limit dose, in preventing CAAs. However, we observed a significant effect of ASA dose on treatment resistance.

Single IVIG $2 \mathrm{~g} / \mathrm{kg} /$ day is the current standard treatment and is recommended as class I in the AHA and JSPCCS guidelines $(4,5)$. During this study period, the impact of high-dose ASA on treatment has decreased (9). Recently, controversies have arisen regarding the optimal dose of ASA to be used. In 2004, the first query regarding high-dose ASA treatment was proposed. Hsieh et al., a Taiwanese group, originally performed IVIG treatment without using ASA in the acute phase, and retrospectively aggregated the antipyretic rate and the incidence of CAAs (11). Their study concluded that $94 \%$ of patients had defervescence within 3 days of IVIG treatment, and 14\% had CAAs, consistent with various reports with IVIG plus ASA. In 2016, Kim et al. studied a large sample of 8,456 children from a retrospective survey of 116 hospitals in South Korea. They reported that compared with low-dose ASA (3-5 mg/kg/day), medium or higher-dose ASA (>30 mg/kg/day) for treatment of acute KD was associated with a higher risk of CAAs after adjustment for cofounders (14). In 2018, a Canadian group reported the results of a multicenter retrospective study (12). They compared the incidence of CAAs with a coronary artery $\mathrm{Z}$ score of $\geq 2.5$ between high-dose aspirin (80-100 $\mathrm{mg} / \mathrm{kg} /$ day) and low-dose aspirin (3-5 mg/kg/day) groups. Non-inferiority for suppression of CAAs in the low-dose group was shown. Our study in a Japanese cohort suggested non-inferiority in the ASA $30-\mathrm{mg}$ Group vs. the ASA 50-mg Group. This result is consistent with a study by a Canadian group, although we used an aspirin dose difference of $20 \mathrm{mg} / \mathrm{kg} /$ day in this study.

Ogata et al. reported that $40 \%$ of KD patients had CAA with $\mathrm{Z}$ score $\geq 2.5$, whereas our results indicated that $12 \%$ of patients had CAAs with $\mathrm{Z}$ score $\geq 2.5$, which was much lower than the previous report. Ogata et al. collected the maximal internal diameter $(\mathrm{mm})$ of the left anterior descending coronary artery and the right coronary artery within 12 weeks after onset (19). We only collected data at 1 month after onset. This may account for the low incidence of CAAs in this study. 
TABLE 2 | Coronary artery outcomes.

(A) Numbers and percentages of patients with CAAs.

\section{ASA 50-mg Group \\ $n=414$ \\ number (\%)}

ASA 30-mg Group

$n=173$

number $(\%)$

All
Small $(Z \geq 2.5, Z<5.0)$
Medium $(Z \geq 5.0, Z<10.0)$
Large $(Z \geq 10.0)$
(B) Unadjusted and adjusted odds ratios.

$18(10.4)$

$14(8.1)$

$3(1.7)$

$1(0.6)$

\begin{tabular}{|c|c|c|c|c|}
\hline & \multicolumn{2}{|c|}{ Unadjusted } & \multicolumn{2}{|c|}{ Adjusted ${ }^{*}$} \\
\hline & $p$-value & Odds ratio $(95 \% \mathrm{Cl})$ & $p$-value & Odds ratio $(95 \% \mathrm{Cl})$ \\
\hline ASA 30-mg Group & 0.346 & $0.760(0.430-1.345)$ & 0.151 & $0.769(0.537-1.101)$ \\
\hline Age $<12$ months & 0.006 & $2.148(1.243-3.711)$ & 0.003 & $1.844(1.237-2.747)$ \\
\hline Sex $=M$ & 0.935 & $0.979(0.592-1.619)$ & 0.455 & $0.872(0.609-1.249)$ \\
\hline Risk score (Kobayashi) & 0.966 & $0.979(0.376-2.553)$ & 0.074 & $1.897(0.939-3.832)$ \\
\hline
\end{tabular}

*Inverse probability weighting analysis.

TABLE 3 | Patients needing second IVIG and third-line treatment.

(A) Numbers of patients needing second IVIG and third-line treatment

\begin{tabular}{lcc}
\hline & $\begin{array}{c}\text { ASA 50-mg Group } \\
\boldsymbol{n}=\mathbf{4 1 4} \\
\text { number (\%) }\end{array}$ & $\begin{array}{c}\text { ASA 30-mg Group } \\
\boldsymbol{n}=\mathbf{1 7 3} \\
\text { number (\%) }\end{array}$ \\
\hline Second IVIG & $95(22.9)$ & $48(27.7)$ \\
Third-line treatment & $21(5.0)$ & $13(7.5)$ \\
\hline
\end{tabular}

(B) Incidence of patients needing second IVIG and third-line treatment.

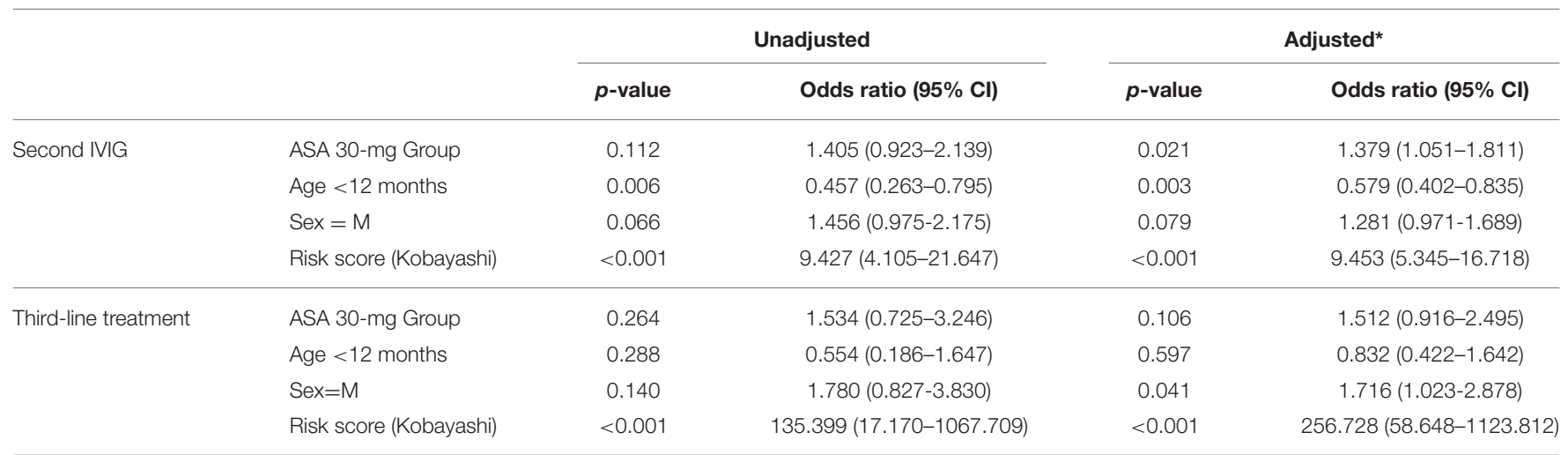

*Inverse probability weighting analysis.

The incidence of additional treatment in the ASA 30-mg Group was significantly higher than in the ASA 50-mg Group; the difference in incidence was 5\%. Studies in Canada and South Korea have shown different incidences of 3 and $6 \%$, respectively $(12,14)$. In this study, it is important to mention the high IVIG resistance rate. In our institution, non-responders were defined as those with body temperature $\geq 37.5^{\circ} \mathrm{C}$ at $48 \mathrm{~h}$ after initiation of primary therapy, which is the standard time point in Japan. This time point is different from that of the US, which may explain the high IVIG resistance rate. Akagi et al. and Lee et al. reported that high-dose ASA could shorten the duration of fever in their studies in a Japanese and Korean cohort, respectively $(20,21)$. Specifically, the duration of fever and the frequency of further treatments are not the same, but our results do not conflict with these previous reports. If the additional treatment is IVIG, the cost of medical care rises and in 
TABLE 4A | Safety outcomes.

(A). Hepatic dysfunction.

\begin{tabular}{|c|c|c|c|c|}
\hline & & $\begin{array}{c}\text { ASA } 50-\mathrm{mg} / \mathrm{kg} / \mathrm{day} \text { Group } \\
n=414, \text { mean } \pm \text { SD }\end{array}$ & $\begin{array}{c}\text { ASA } 30-\mathrm{mg} / \mathrm{kg} / \mathrm{day} \text { Group } \\
\mathrm{n}=173, \text { mean } \pm \text { SD }\end{array}$ & $p$-value \\
\hline \multicolumn{2}{|c|}{ Incidence of patients with hepatic dysfunction *a , \% } & $15 \%$ & $17 \%$ & $0.078^{\star b}$ \\
\hline & Alanine aminotransferase & $43.7 \pm 66.8$ & $33.7 \pm 52.7$ & $0.057^{\star c}$ \\
\hline
\end{tabular}

*a Defined as aspartate aminotransferase $>50 \mathrm{U} / \mathrm{L}$ and alanine aminotransferase $>50 \mathrm{U} / \mathrm{L}$ at convalescent phase.

*b Pearson's $\chi^{2}$ test.

${ }^{\star c}$ Welch's t-test.

\section{TABLE 4B |}

(B). Hemoglobin.

\begin{tabular}{lccr}
\hline & $\begin{array}{c}\text { ASA 50-mg Group, } \\
\text { mean (SD)/percentage }\end{array}$ & $\begin{array}{c}\text { ASA 30-mg Group, } \\
\text { mean (SD)/percentage }\end{array}$ & $p$ p-value \\
\hline Pre IVIG, g/dL & $11.3 \pm 1.2$ & $11.6 \pm 1.0$ & $0.045^{\star \star a}$ \\
Post IVIG, g/dL & $10.9 \pm 1.2$ & $11.1 \pm 1.4$ & $0.833^{\star \star a}$ \\
Difference (post-pre), g/dL & $-0.4 \pm 1.1$ & $-0.5 \pm 1.5$ & $p=0.895^{\star a}$ \\
\hline
\end{tabular}

*aWelch's t-test.

Japan, the facilities go into deficit. In addition, the hospitalization period is extended and the patient burden increases. Thus, 50 $\mathrm{mg} / \mathrm{kg} /$ day ASA would be superior to $30 \mathrm{mg} / \mathrm{kg} /$ day ASA in terms of medical costs.

Regarding adverse events, Kuo et al. reported a decrease in hemoglobin after IVIG treatment in patients who received highdose ASA (13). In our Japanese cohort, however, anemia did not worsen in the ASA 50-mg Group, although hemoglobin levels decreased in both groups as previously reported (22). Japanese individuals have limited hepatic metabolism of aspirin, and liver dysfunction is more frequent at the high dose of 80 $100 \mathrm{mg} / \mathrm{kg} /$ day ASA. Therefore, the high dose is not approved in Japan. The incidence of liver dysfunction was similar between the two groups. There were no severe bleeding events either. In this study period, we had no patients with digestive symptoms. According to Huang et al., digestive symptoms were the most common side effects of ASA therapy (23).

There are several limitations of this study. The first limitation is selection bias in study patients. Patients who were enrolled in a clinical study (16) were excluded from the ASA 30-mg Group. The odds ratio of the ASA 30-mg Group vs. that of the ASA 50mg Group in the incidence of CAAs was $0.769(<1.0)$, whereas that in the incidence of treatment resistance was $1.379(>1.0)$. Usually, the two odds ratios would be proportional. Exclusion of patients with severe disease who were enrolled in a clinical study could have influenced the primary endpoint. Second, we excluded patients who had preexisting CAAs before treatment, which was diagnosed according to the Japanese criteria (15). CAAs are underdiagnosed according to the Japanese criteria, and this study may have included patients with CAAs before treatment defined by the AHA guidelines, which diagnose CAA based on a $\mathrm{Z}$ score $\geq 2.5$. Third, the aspirin dose difference between the two groups is not large. The government has approved $30-50 \mathrm{mg} / \mathrm{kg} /$ day for $\mathrm{KD}$ and this observational retrospective study was performed using the study design within this dose range. The 4th limitation is that this is a retrospective and single-center study.

A prospective study is currently underway in Taiwan comparing IVIG plus ASA low-dose and high-dose initial treatment (24). We are eagerly awaiting the results of that study.

In conclusion, the suppression of the development of CAAs, which is the ultimate goal of treatment for $\mathrm{KD}$, might not be inferior with $30 \mathrm{mg} / \mathrm{kg} /$ day ASA compared with $50 \mathrm{mg} / \mathrm{kg} /$ day in Japanese patients. However, the administration of ASA 50 $\mathrm{mg} / \mathrm{kg} /$ day could decrease the need for additional treatment without increasing adverse events.

\section{DATA AVAILABILITY STATEMENT}

All datasets generated for this study are included in the article/supplementary material.

\section{ETHICS STATEMENT}

The studies involving human participants were reviewed and approved by Research Ethics Board, Tokyo Women's Medical University (3636-R2). Written informed consent from the participants' legal guardian/next of kin was not required to participate in this study in accordance with the national legislation and the institutional requirements. 


\section{AUTHOR CONTRIBUTIONS}

$\mathrm{HH}$ and $\mathrm{TM}$ designed the study. $\mathrm{HH}$ reviewed YI analyzed data and wrote the manuscript. JT, KY, TH, and KA did critical review for the manuscript.

\section{REFERENCES}

1. Kawasaki T. Acute febrile mucocutaneous syndrome with lymphoid involvement with specific desquamation of the fingers toes in children (in Japanese). Arerugi. (1967) 16:178-222.

2. Gordon JB, Kahn AM, Burns JC. When children with Kawasaki disease grow up: myocardial complications in adulthood. J Am Coll Cardiol. (2009) 54:1911-20. doi: 10.1016/j.jacc.2009.04.102

3. Newburger JW, Takahashi M, Burns JC. Kawasaki disease. J Am Coll Cardiol. (2016) 67:1738-49. doi: 10.1016/j.jacc.2015.12.073

4. McCrindle BW, Rowley AH, Newburger JW, Burns JC, Bolger AF, Gewitz M, et al. Diagnosis, treatment, and long-term management of Kawasaki disease: a scientific statement for health professionals from the American heart association. Circulation. (2017) 135:e927-99. doi: 10.1161/CIR.0000000000000484

5. Research committee of the Japanese Society of Pediatric Cardiology and Cardiac Surgery: Committee for development of guidelines for medical treatment of acute Kawasaki disease. Guidelines for medical treatment of acute Kawasaki disease : report of the Research Committee of the Japanese Society of Pediatric Cardiology and Cardiac Surgery (2012 revised version). Peditr Int. (2014) 56:135-58. doi: 10.1111/ped.12317

6. Kusakawa S, Tatara K. Acute treatment research on kawasaki disease (the second report)-prospective study by 3 trial groups of aspirin, flurbiprofen, predonisolone + dipyridamole, results at 1 year after onset-. Jap J Pediatr. (1985) 89:814-8.

7. Makino N, Nakamura Y, Yashiro M, Ae R, Tsuboi S, Aoyama Y, et al. Descriptive epidemiology of Kawasaki disease in Japan, 2011-2012; from the results of the $22^{\text {nd }}$ nationwide survey. J Epidemiol. (2015) 25:239-45. doi: 10.2188/jea.JE20140089

8. Koren G, Rose V, Lavi S, Rowe R. Probable efficacy of high-dose salicylates in reducing coronal involvement in Kawasaki disease. JAMA. (1985) 254:767-9. doi: $10.1001 /$ jama.254.6.767

9. Terai M, Shulman ST. Prevalence of coronal artery abnormalities in Kawasaki disease is highly dependent on gamma globulin dose but independent of salicylate dose. J Pediatr. (1997) 131:888-93. doi: 10.1016/S0022-3476(97)70038-6

10. Durongpisitkul K, Gururaj VJ, Park JM, Martin CF. The prevention of coronary artery aneurysm in Kawasaki disease: meta-analysis on the efficacy aspirin and immunoglobulin treatment. Pediatrics. (1995) 96:1057-61.

11. Hsieh KS, Weng KP, Lin CC, Huang TC, Lee CL, Huang SM. Treatment of acute Kawasaki disease: aspirin's role in the febrile stage revisited. Pediatrics. (2004) 114:689-93. doi: 10.1542/peds.2004-1037

12. Dallaire F, Fortier-Morissette Z, Biais S, Dhanrajani A, Basodan D, Renaud C, et al. Aspirin dose and prevention of coronal artery abnormalities in kawasaki disease. Pediatrics. (2017) 139:e20170098. doi: 10.1542/peds.2017-0098

13. Kuo HC, Lo MH, Hsieh KS, Guo MM, Huang YH. High-dose aspirin is associated with anemia and does not confer benefit to disease outcomes in kawasaki disease. PLOS ONE. (2015) 10:e0144603. doi: 10.1371/journal.pone.0144603

14. Kim GB, Yu JJ, Yoon KL, Jeong SI, Song YH, Han JW, et al. Medium- or highdose acetylsalicylic acid for acute Kawasaki disease and patient outcomes. $J$ Pediatr. (2017) 184:125-9. doi: 10.1016/j.jpeds.2016.12.019

\section{FUNDING}

The authors declare that this study received funding from Nihon Pharmaceutical Co. Ltd, and Teijin Pharma Limited. The funders were not involved in the study design, collection, analysis, interpretation of data, writing of this article, or the decision to submit for publication.

15. Research Committee on Kawasaki Disease. Report of Subcommittee on Standardization of Diagnostic Criteria and Reporting of Coronary Artery Lesions in Kawasaki Disease. Tokyo: Ministry of Health and Welfare (1984) (in Japanese).

16. Hamada H, Suzuki H, Onouchi Y, Ebata R, Terai M, Fuse S, et al. Efficacy of primary treatment with immunoglobulin plus cyclosporine for prevention of coronary artery abnormalities in Kawasaki disease patients predicted to be at increased risk of IVIG non-response (KAICA study): a controlled, phase 3, randomised, open-label, blinded-endpoints trial. Lancet. (2019) 393:1128-37. doi: 10.1093/rheumatology/kez063.031

17. Kobayashi T, Fuse S, Sakamoto N, Mikami M, Ogawa S, Hamaoka K, et al. A new $\mathrm{Z}$ score curve of the coronary arterial internal diameter using the lambdamu-sigma method in a pediatric population. J Am Soc Echocardiogr. (2015) 29:794-801.e29. doi: 10.1016/j.echo.2016.03.017

18. Kobayashi $\mathrm{T}$, Inoue $\mathrm{Y}$, Takeuchi K, Okada $\mathrm{Y}$, Tamura K, Tomomasa $\mathrm{T}$, et al. Prediction of intravenous immunoglobulin unresponsiveness in patients with Kawasaki disease. Circulation. (2006) 113:2606-12. doi: 10.1161/CIRCULATIONAHA.105.592865

19. Ogata S, Tremoulet AH, Sato Y, Ueda K, Shimizu C, Sun X., et al. Coronary artery outcomes among children with Kawasaki disease in the United States and japan. Int J Cardiol. (2013) 168:3825-8. doi: 10.1016/j.ijcard.2013.06.027

20. Akagi $\mathrm{T}$, Kato $\mathrm{H}$, Inoue $\mathrm{O}$, Sato $\mathrm{N}$. A study on the optimal dose of aspirin therapy in kawasaki disease-clinical evaluation and arachidonic acid metabolism. Kurume Med J. (1990) 37:203-8. doi: 10.2739/kurumemedj.37.203

21. Lee G, Lee SE, Hong YM, Sohn S. Is high-dose aspirin necessary in the acute phase of kawasaki disease? Korean Circ J. (2013) 43:182-6. doi: 10.4070/kcj.2013.43.3.182

22. Takeuchi M, Ito S, Nakamura M, Kawakami K. Changes in hemoglobin concentrations post-immunoglobulin therapy in patients with Kawasaki disease: a population-based study using a claims database in Japan. Paediatr Drugs. (2018) 20:585-91. doi: 10.1007/s40272-018-0316-y

23. Huang X, Huang P, Zhang L, Xie X, Xia S, Gong F, et al. Is aspirin necessary in the acute phase of Kawasaki disease? J Paediatr Child Health. (2018) 54:661-4. doi: $10.1111 /$ jpc.13816

24. Kuo HC, Guo MM, Lo MH, Hsieh KS, Huang YH. Effectiveness of intravenous immunoglobulin alone and intravenous immunoglobulin combined with high-dose aspirin in the acute stage of kawasaki disease: study protocol for a randomized controlled trial. BMC Pediatr. (2018) 18:200. doi: $10.1186 / \mathrm{s} 12887-018-1180-1$

Conflict of Interest: The authors declare that the research was conducted in the absence of any commercial or financial relationships that could be construed as a potential conflict of interest.

Copyright (c) 2020 Ito, Matsui, Abe, Honda, Yasukawa, Takanashi and Hamada. This is an open-access article distributed under the terms of the Creative Commons Attribution License (CC BY). The use, distribution or reproduction in other forums is permitted, provided the original author(s) and the copyright owner(s) are credited and that the original publication in this journal is cited, in accordance with accepted academic practice. No use, distribution or reproduction is permitted which does not comply with these terms. 